\title{
Idiopathic bronchial hemorrhage: a rare but catastrophic complication in cardiac surgery
}

\author{
Takeshi Uzuka ${ }^{1,2^{*}}$, Masanori Nakamura', Tomohiro Nakajima', Shinichi Kusudoh', Hiroaki Usubuchi', \\ Akihiko Tanaka ${ }^{1}$ and Noriyasu Watanabe ${ }^{1}$
}

\begin{abstract}
Background: Hemoptysis is a common complication in all kinds of surgery. However, it is rarely critical because it resolves with or without intervention.

Case presentation: Here the authors present what is believed to be an unprecedented report of a case involving a fatal idiopathic bronchial hemorrhage complication during cardiac surgery. Eighty-five-year-old female with severe aorticvalve stenosis had elective aortic valve replacement. Subsequently, she developed diffuse bilateral severe idiopathic bronchial hemorrhage which required maximum intervention such as external bronchial ligation, V-A ECMO, coil embolization of bronchial artery and internal airway blockage by spigot.
\end{abstract}

Conclusions: Airway bleeding is not a rare complication in cardiac surgery, but this case should increase awareness of this potentially life threatening perioperative complication.

Keywords: Idiopathic bronchial hemorrhage, Complication, Cardiac surgery, Hemoptysis

\section{Background}

Airway bleeding during or after heart surgery is common, but is rarely reported because it is generally minor and resolves spontaneously in most cases. Here the authors report an unusual case of exsanguinating diffuse airway bleeding during cardiac surgery. The complication required aggressive intervention measures such as extra-corporeal membrane oxygenation (ECMO), bronchial ligation, bronchial artery coil embolization and internal airway blockage using an intrabronchial spigot.

\section{Case presentation}

The case involved an 85-year-old female with congestive heart failure caused by severe aortic valve stenosis. Aortic valve replacement with a bioprosthetic valve was conducted electively. After the ascending aorta was unclamped, anesthetist noticed blood coming up from

\footnotetext{
* Correspondence: Uzuka@aol.com

${ }^{1}$ Cardiothoracic Surgery, Sapporo City General Hospital, Sapporo, Hokkaido 060-8604, Japan

${ }^{2}$ Cardiovascular Surgery, Sapporo City General Hospital, North 11 West 13 Chuo-ku, Sapporo, Hokkaido 060-8604, Japan
}

the endotracheal tube. Intraoperative flexible bronchoscopy confirmed massive hemoptysis coming up from all peripheral bronchi and mainly from the bilateral inferior lobes. The left chest was inspected through additional anterolateral thoracotomy connected perpendicularly to median sternotomy wound at 4th intercostal space. And the left hilum was exposed and lower bronchus was ligated externally to reduce the amount of intrabronchial bleeding. Repeated bronchoscopy showed persisting large-volume airway bleeding (Additional file 1: Video S1) and weaning cardiopulmonary bypass was impossible due to a reduced tidal volume of up to around $50 \mathrm{ml}$ caused by severe peripheral airway obstruction. Groin cannulated veno-arterial ECMO with heparin coated circuit was initiated as a substitute for conventional cardiopulmonary bypass, and heparin was reversed precipitously with full dose of protamine sulfate. To treat the persistent airway bleeding, the chest wound was closed and the patient was shifted to a catheterization laboratory for bronchial artery embolization. Intraoperative total blood loss from the airway was over $4000 \mathrm{ml}$. 


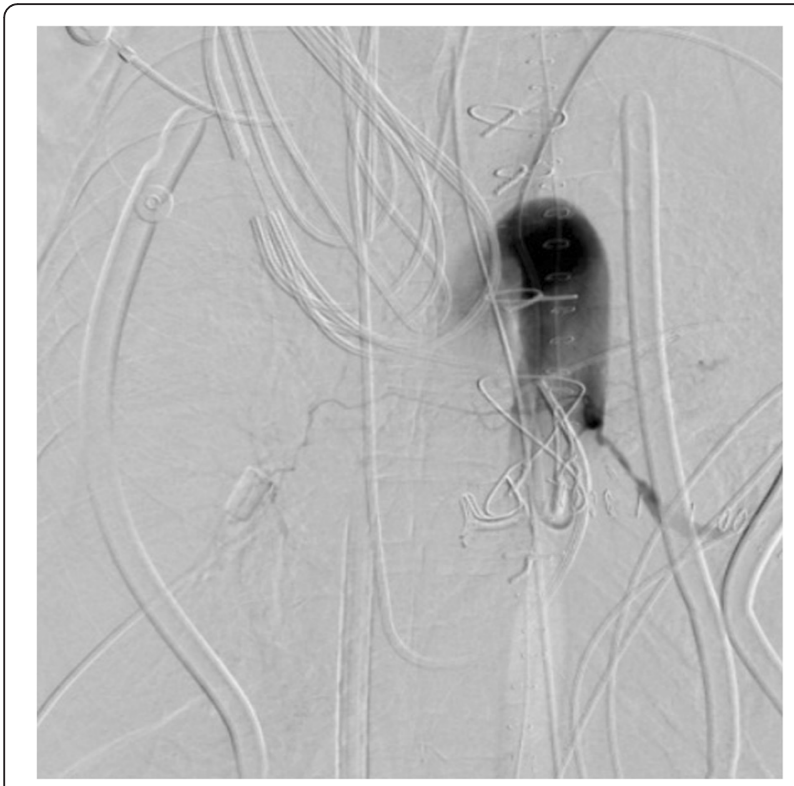

Fig. 1 Bronchial artery angiography and embolization. The bronchus in the left lower lobe was enhanced by bronchial artery angiography

Angiography confirmed massive bronchial artery bleeding into the left lower bronchus (Fig. 1). However, diffuse bronchial artery bleeding was observed in the left upper lobe and right lower lobe as well. Embolization of the bilateral bronchial artery was conducted successfully. However, hemoptysis continued and repeated bronchoscopy confirmed ongoing diffuse bleeding. The right lower bronchus was blocked internally with an Endobronchial Watanabe Spigot (Nobatech, Cedex, France). Even after these aggressive interventions, diffuse hemorrhage persisted.

Eventually the amount of hemoptysis reduced on day four, and external ligation of the left inferior bronchus was finally released. The patient's hemodynamics showed slight improvement on day five with, and a decision was made to convert to Venous-Venous ECMO. However, the patient crashed again and passed away from multiorgan failure on day six.

\section{Discussion}

The term used for the event is idiopathic bronchial hemorrhage. This may overlap but differs from the more documented diffuse alveolar hemorrhage, which is characterized by diffuse microvascular bleeding. In this case, the bronchial artery was responsible for the exanguinating hemoptysis, and no pre-existing lung disease was suggested. Accordingly, the complication was diagnosed as idiopathic bronchial hemorrhage. To the authors' knowledge, this is the first report of idiopathic bronchial hemorrhage during cardiac surgery, which was diagnosed clearly by bronchoscopy and bronchial angiography.

Most cases of reported exsanguinating hemoptysis (defined as blood loss exceeding $1000 \mathrm{ml}$ at a rate of at least $150 \mathrm{ml} / \mathrm{h}[1,2])$ have been related to pulmonary artery catheter (PAC) induced trauma [3-6]. Although localization of the site of perforation from PAC is impossible as there is not one connecting tunnel but more or less a series of small bleeding channels, the authors do not believe that PAC injury is the cause of this massive hemoptysis because intraoperative bronchoscopy showed diffuse bleeding from both lungs. For this bronchoscopy finding, we could not isolate or remove the damaged lung.

There is no doubt that systemic heparinization in cardiac surgery triggered the diffuse bronchial hemorrhage. Complete heparin reversal and expeditious weaning from cardiopulmonary bypass is reported to be the best and the only way to manage major hemoptysis [1-5]. However, in this case, due to the massive airway bleeding, circulation and oxygenation could not be maintained without mechanical support. The authors believed that the only following option was to reverse heparin fully and implement bronchial arterial embolization in the catheterization laboratory. However, it would have been effective to block pulmonary artery branch by inflating the balloon of the PAC because there is a certain level of microvascular connection between bronchial and pulmonary circulation [7].

Underlying pulmonary disease such as bronchiectasia or tuberculosis can also cause perioperative hemoptysis. Pulmonary capillaritis such as Wegener's granulomatosis or Goodpasture syndrome are also known to be related to pulmonary hemorrhage [8]. Although preoperative chest $\mathrm{CT}$ and spirometry did not suggest any underlying pulmonary disease, it cannot be excluded because postmortem autopsy was declined by the patient's family.

\section{Conclusion}

In summary, this was a rare case of diffuse exsanguinating hemoptysis during cardiac surgery. Even after all the aggressive intervention and intensive care administered, the patient's respiratory status failed to show improvement in terms of lung compliance and oxygenation. Practicing cardiothoracic surgeons should note this unusual but catastrophic perioperative complication.

\section{Ethics and patient consent}

All authors have approved the manuscript. Patient's family has agreed with submission of the case report. Upon acceptance, authors will transfer copyright to the Publisher. All authors have no ethical problem or conflicts of interest to declare. 


\section{Additional file}

Additional file 1: Video S1. Flexible bronchoscopy during the operation. Exanguinating airway bleeding was observed. (MP4 40768 kb)

\section{Competing interests}

The authors declare that they have no competing interests.

\section{Authors' contributions}

Author $1(T A)$ is corresponding author who wrote the script. Patient described in this case report was under Author 1's care. Author 2 (MN) have made substantial contributions to conception and design. He also has been involved in revising it critically for important intellectual content. Author 3 (TN) has been involved in drafting the manuscript. Author 4 (SK) and Author $5(\mathrm{HU})$ and Author 6 (AT) and Author 7 (NW) have given final approval of the version to be published and agreed to be accountable for all aspects of the work in ensuring that questions related to the accuracy or integrity of any part of the work are appropriately investigated and resolved. All authors read and approved the final manuscript.

Received: 7 October 2015 Accepted: 23 April 2016

Published online: 05 May 2016

\section{References}

1. Smythe R, Gorman R, DeCampli W, Spray T, Kaiser L, Acker M. Management of exsanguinating hemoptysis during cardiopulmonary bypass. Ann Thorac Surg. 1999;67:1288-91.

2. Garzon AA, Cerruti MM, Golding ME. Exsanguinating hemoptysis. J Thorac Cardiovasc Surg. 1982;84:829-33.

3. McDaniel DD, Stone JG, Faltas AN, Khambatta HJ, Thys DM, Antunes AM, et al. Catheter-induced pulmonary artery hemorrhage. Diagnosis and management in cardiac operations. J Thorac Cardiovasc Surg. 1981;82:1-4.

4. Barash PG, Nardi D, Hammond G, Walker-Smith G, Capuano D, Laks H, et al. Catheter-induced pulmonary artery perforation. Mechanisms, management and modifications. J Thorac Cardiovasc Surg. 1981;82:5-12.

5. Fleisher AG, Tyers GFO, Manning GT, Nelems B. Management of massive hemoptysis secondary to catheter-induced perforation of the pulmonary artery during cardiopulmonary bypass. Chest. 1989:95:1340-1.

6. Schramm R, Abugameh A, Tscholl D, Scafers HJ. Managing pulmonary artery catheter-induced pulmonary hemorrhage by bronchial occlusion. Ann Thorac Surg. 2009;88:284-7.

7. Dopfmer UR, Braun JP, Grosse J, Hotz H, Duveneck K, Schneider MB. Treatment of severe pulmonary hemorrhage after cardiopulmonary bypass by selective, temporary balloon occlusion. Anesth Analg. 2004;99(5):1280-2.

8. Lara AR, Shwarz MI. Diffuse alveolar hemorrhage. Chest. 2010;137(5):1164-71.

\section{Submit your next manuscript to BioMed Central and we will help you at every step:}

- We accept pre-submission inquiries

- Our selector tool helps you to find the most relevant journal

- We provide round the clock customer support

- Convenient online submission

- Thorough peer review

- Inclusion in PubMed and all major indexing services

- Maximum visibility for your research

Submit your manuscript at www biomedcentral.com/submit

) Biomed Central 